\title{
Clinical characteristics, patterns of lipid-lowering medication use, and health care resource utilization and costs among patients with atherosclerotic cardiovascular disease
}

This article was published in the following Dove Press journal:

Vascular Health and Risk Management

\author{
Thomas P Power' \\ Xuehua $\mathrm{Ke}^{2}$ \\ Zhenxiang Zhao ${ }^{3}$ \\ Nicole Gidaya Bonine ${ }^{2}$ \\ Mark J Cziraky² \\ Michael Grabner ${ }^{2}$ \\ John J Barron ${ }^{2}$ \\ Ralph Quimbo² \\ Burkhard Vangerow ${ }^{3}$ \\ Peter P Toth ${ }^{4,5}$ \\ 'AIM Specialty Health, Chicago, IL, \\ ${ }^{2}$ HealthCore, Inc., Wilmington, DE, \\ ${ }^{3}$ Eli Lilly and Company, Indianapolis, \\ IN, ${ }^{4} \mathrm{CGH}$ Medical Center, Sterling, IL, \\ 5ohns Hopkins University School of \\ Medicine, Baltimore, MD, USA
}

Correspondence: Xuehua Ke HealthCore, Inc., 123 Justison Street, Suite 200, Wilmington, DE 1980 I, USA

Tel +l 3022302159

Fax + I 3022302020

Email xke@healthcore.com

\begin{abstract}
Purpose: The aim of this study was to investigate real-world patient characteristics, medication use, and health care resource utilization (HCRU) and costs among patients with clinical atherosclerotic cardiovascular disease (ASCVD) as defined by 2013 American College of Cardiology/ American Heart Association (ACC/AHA) guidelines, to examine burden of disease and unmet needs, such as potential undertreatment.

Patients and methods: This retrospective cohort study utilized a nationally representative managed care database to identify newly diagnosed ASCVD patients between January 1, 2007, and November 30, 2012 (index = first ASCVD diagnosis date) in the USA. Patients had $\geq 12$ month pre-index (baseline) and $\geq 12$-month post-index (follow-up) health plan enrollment and no baseline lipid-lowering medication (LLM). Patient characteristics, LLM utilization patterns, HCRU, and costs were examined for all patients and by subgroups based on LLM use pattern and/or follow-up low-density lipoprotein cholesterol (LDL-C) levels.

Results: A total of 128,017 ASCVD patients were identified with a mean (SD) age of 59 (13) years, $43.1 \%$ female, and $48.8 \%$ with $\geq 36$-month follow-up. Within 12 -month follow-up, $10.6 \%$ had high-intensity statins and $56.9 \%$ had no LLM fills. Baseline mean (SD) all-cause costs were $\$ 8,852$ ( $\$ 25,608$ ). At 12 -month follow-up, mean (SD) all-cause and ASCVD-related costs were $\$ 31,443(\$ 54,040)$ and $\$ 20,289(\$ 45,159)$, respectively. The 36-month analyses showed similar distributions. Multivariable analyses showed that age, gender, region, health insurance type, baseline comorbidities, baseline use of specific medications, baseline lipid profiles, and index ASCVD type were significantly associated with all-cause and ASCVD-related health care costs. Conclusion: Patients have nonoptimal treatment for ASCVD and substantial HCRU and costs associated with residual risk. Unmet needs and cost burdens of ASCVD patients merit additional investigation.
\end{abstract}

Keywords: ASCVD, low-density lipoprotein cholesterol, lipid-lowering medications, health care resource utilization and costs, statins, treatment patterns, guidelines, real-world evidence

\section{Introduction}

Clinical atherosclerotic cardiovascular disease (ASCVD), constituted of acute coronary syndrome (ACS), history of myocardial infarction, stable or unstable angina, coronary or other arterial revascularization, stroke, transient ischemic attack, or peripheral arterial disease presumed to be of atherosclerotic origin, is the leading cause of death for both men and women in the USA. ${ }^{1}$ Approximately 370,000 deaths annually in the USA are attributable to coronary heart disease (CHD). ${ }^{1}$ Heart-related conditions could intensify 
as the US population ages - the $\geq 65$-year-old population is projected to approximately double by $2030 .^{2}$ The American Heart Association (AHA) forecasts that $40.5 \%$ of the US population will have some form of cardiovascular disease by 2030 - and between 2010 and 2030, the total direct medical costs of cardiovascular disease will increase threefold from $\$ 273$ billion to $\$ 818$ billion. $^{3}$

Hypercholesterolemia has been identified as one of the major risk factors for ASCVD, 4,5 and numerous trials have demonstrated the clinical benefits of low-density lipoprotein cholesterol (LDL-C) reduction ${ }^{6-10}$ in both primary and secondary prevention settings. ${ }^{11,12}$

The 2013 American College of Cardiology (ACC)/AHA guidelines for the treatment of hypercholesterolemia represent an important shift from the previous approach, which entailed treatment to achieve risk-stratified LDL-C goals defined by estimated 10-year risk for an acute cardiovascular event. ${ }^{5}$ Specifically, the 2013 guidelines identified four major statin benefit groups: 1) individuals with clinical ASCVD, 2) individuals with primary elevations of LDL-C $\geq 190 \mathrm{mg} / \mathrm{dL}$, 3 ) individuals with diabetes aged 40-75 years with LDL-C $70-189 \mathrm{mg} / \mathrm{dL}$ and without clinical ASCVD, or 4) individuals without clinical ASCVD or diabetes with LDL-C 70-189 mg/ $\mathrm{dL}$ and estimated 10-year ASCVD risk $\geq 7.5 \%{ }^{5}$

Among patients with clinical ASCVD, high-intensity statin therapy is recommended for those aged $\leq 75$ years, unless contraindicated. Moderate-intensity statin therapy is recommended for patients aged $>75$ years or those who are not candidates for high-intensity statins. In addition, no guideline recommendations are made for or against specific LDL-C or non-high-density lipoprotein cholesterol (nonHDL-C) goals for the primary and secondary prevention of ASCVD. ${ }^{5}$

It has been estimated that use of the 2013 guidelines as an alternative to the National Cholesterol Education Program Adult Treatment Panel III (NCEP ATP-III) recommendations $^{13}$ would increase statin eligibility by $11 \%$ in the USA, or by 12.8 million patients. ${ }^{14} \mathrm{~A}$ small retrospective study $(\mathrm{N}=3,203)$ based on electronic health records to assess the impact of the new guidelines concluded that broad adoption of the 2013 guidelines would likely expand statin prescription rates among patients in the fourth statin benefit group as defined by the 2013 guidelines. ${ }^{15}$ Another estimate by Tran et $a 1^{16}$ suggested that, among potential candidates for cholesterol-lowering treatments, compared to the benchmarks in 2013, there would be a $25 \%$ increase in the proportion of patients treated with statins over 2014-2016, during which prescriptions for non-statin cholesterol-lowering agents will decrease by $68 \%$. Additional evaluation of ASCVD patient clinical characteristics, treatment patterns, and health care resource utilization (HCRU) and costs in the short term and long term prior to implementation of the 2013 guidelines using both the old and new guideline measures may help to better understand the potential impact of the 2013 guidelines on patients with clinical ASCVD.

This study investigated real-world patient demographic and clinical characteristics, patterns of lipid-lowering medication (LLM) utilization, and HCRU and costs, specifically through the lens of the old and new guideline measures, among patients with clinical ASCVD as defined by the 2013 ACC/AHA guidelines ${ }^{5}$ to better understand the burden of disease and unmet needs in this population.

\section{Patients and methods}

\section{Study design and patient identification}

This observational, retrospective cohort study utilized medical and pharmacy claims along with laboratory results of enrollees in 14 regionally dispersed health plans in the USA from the broadly, nationally representative ${ }^{17}$ HealthCore Integrated Research Database $\left(\mathrm{HIRD}^{\circledR}\right)$, for the study period of January 1, 2006, through November 30, 2013. The targeted study population of interest consisted of patients with incident clinical ASCVD. To identify this target study population within the HIRD, patients with an ASCVD diagnosis (including ACS, CHD, atherosclerotic cerebrovascular disease [ACD], and peripheral artery disease [PAD]) were selected during the intake period (January 1, 2007, to November 30, 2012). ASCVD diagnosis was defined as either $\geq 1$ inpatient or emergency room (ER) visit with any ASCVD ICD-9-CM diagnosis codes in the primary diagnosis position, or $\geq 2$ physician office or other outpatient visits that were $\geq 30$ days apart with ASCVD ICD-9-CM diagnosis codes within the same ASCVD group (Table S1). The earliest medical claim that qualified as an ASCVD diagnosis for an inpatient, ER, or outpatient encounter within the intake period was defined as the index date, which represents the date of incident clinical ASCVD for each patient. All study data were managed in strict compliance with the Health Insurance Portability and Accountability Act (HIPAA) Privacy Rule, and data de-identification procedures were employed to preserve patient anonymity and confidentiality throughout the study process. Institutional review board (IRB) approval was not required for this administrative claimsbased study as HealthCore, Inc. is a business associate of the covered entities for which the administrative claims data was used and maintains data use agreements to conduct research using that data in the form of a limited data set. 


\section{Inclusion/exclusion criteria}

For inclusion, patients were required to be $\geq 18$ years on the index date, be enrolled only in commercial or Medicare Advantage Plans during the study period, and have $\geq 12$ month pre- and $\geq 12$-month post-index continuous health plan enrollment. To focus on patients with new-onset clinical ASCVD in relation to the index date, patients with $\geq 1$ ASCVD claim(s) in the 12-month pre-index period were excluded. In order to focus on initiation and subsequent utilization of LLM, we excluded patients with any LMM claim during the 12-month pre-index period.

\section{Study measures}

\section{Demographic and clinical characteristics}

Patients' demographic characteristics (on index date) included age, gender, health plan type (health maintenance organization [HMO], preferred provider organization [PPO], or others), Medicare Advantage coverage, and geographic region of their health plan. Clinical characteristics included the type of ASCVD on index date and baseline (12-month pre-index period) clinical characteristics such as Quan-Charlson Comorbidity Index (QCI), ${ }^{18}$ selected comorbidities of interest (including chronic kidney disease, diabetes, dyslipidemia, hypertension, obesity, anxiety, depression, and pain), use of non-LLM, and lipid panel values (for a subset of patients with directly available laboratory results). Lipid panel values including LDL-C, highdensity lipoprotein cholesterol (HDL-C), triglycerides, total cholesterol, and non-HDL-C were measured at baseline and at 12- and 36-month follow-up. Baseline lipid panel values were measured in the year prior to the index date including up to 15 days after the index date; follow-up lipid panel values were measured at the end of the 12-month followup (index date +364 days \pm 90 days) and at the end of the 36-month follow-up (index date $+1,094$ days \pm 90 days). In cases with $\geq 1$ baseline value for the same lipid measure, the result closest to index date was used. When multiple follow-up lipid values were available, the results closest to the end date of each discrete follow-up period (12- and 36-month periods) were used for evaluation.

\section{LLM utilization patterns}

The index LLM was defined as the first LLM prescription (either monotherapy or combination therapy) filled by a patient within 6 months following the diagnosis of ASCVD. The earliest fill date of the index LLM was defined as the index fill date. The index LLM dose titration (up, down, and no change), discontinuation/persistence, switching, and augmentation were examined within both the 12- and 36-month follow-up periods among a subset of patients who initiated a monotherapy LLM on the index fill date and had at least 12 and 36 months of observational follow-up time from index date.

Discontinuation of the index LLM was defined as no refill for the index LLM within 45 days following the depletion of the preceding fill's days of supply per the pharmacy claim. The evaluation of discontinuation of the index LLM (i.e., time until discontinuation and persistence) was limited to the first observed discontinuation and did not account for subsequent restarts of the index LLM. A switch from the index LLM was defined as a fill of a non-index LLM within 45 days from the first discontinuation date and no more fills of the index LLM within 6 months after the discontinuation date. Evaluation of switches from the index LLM (i.e., time to a switch from the index LLM) was limited to the first observed switch only. Persistence was defined as the time from initiation until discontinuation of the index LLM; in cases without discontinuation, persistence was measured as the time from initiation of the index LLM to the end of follow-up. Augmentation was defined as the addition of a non-index LLM while a patient was persistent with the index LLM. Overall, LLM use patterns were examined at 12-month follow-up among all patients and at 36-month follow-up among those with $\geq 36$-month post-index health plan enrollment.

\section{HCRU and costs}

All-cause and ASCVD-related HCRU and costs were derived from medical claims for inpatient hospitalizations, ER visits, physician office visits, and other outpatient visits/services and from pharmacy claims for prescription medications. HCRU and costs occurring on the index date were included in the follow-up period. Costs incorporated both health plan and patient payments. Patient out-of-pocket costs included coinsurance, deductibles, co-payments, and any other patient outlays for specific claims. ASCVD-related medical costs were derived from medical claims with any ICD-9-CM diagnosis code(s) for ASCVD during the 12- and 36-month follow-up periods. ASCVD-related pharmacy costs were computed from pharmacy claims for ASCVD-related medications including LLMs, anti-claudication medications, antidiabetic medications, antihypertensive medications, digoxin, prescription antiplatelet and anticoagulant medications, and prescription omega 3 fatty acids during the 12- and 36-month follow-up periods. All costs were adjusted to 2013 US\$ values based on the consumer price index for medical care from the US Bureau of Labor Statistics. ${ }^{19}$ 


\section{Patient subgroups}

Patients were categorized into different non-mutually exclusive subgroups based on their index LLM therapy or LDL-C status observed during the study follow-up: 1) whether or not patients were on high-intensity statins (defined as statins lowering LDL-C by approximately $\geq 50 \%,{ }^{5}$ including atorvastatin 40 or $80 \mathrm{mg}$ and rosuvastatin 20 or $40 \mathrm{mg}^{3}$ ) in all four calendar quarters after the index date (or, for patients with 36 months of follow-up, at least two calendar quarters in each year of follow-up), 2) whether or not patients had $>50 \%$ follow-up LDL-C reduction, 3) whether or not patients had follow-up LDL-C $<70 \mathrm{mg} / \mathrm{dL}$, and 4) whether or not patients had follow-up LDL-C $<100 \mathrm{mg} / \mathrm{dL}$ at 12 - and 36-month follow-up.

\section{Statistical analysis}

Descriptive statistics, including mean (SD and median) and absolute/relative frequencies for continuous and categorical data, respectively, were reported. Due to the non-normal distribution and skewed nature of the cost data, generalized linear models (GLMs) with gamma distribution and log link ${ }^{20}$ were used to examine the association of patient factors such as baseline patient demographic and clinical characteristics with total all-cause and ASCVD-related health care costs (dependent variables) within 12 months of follow-up.

\section{Results}

\section{Demographic and clinical characteristics}

Study patients $(\mathrm{N}=128,017)$ had a mean ( $\mathrm{SD}$, median) age of $59(13,58)$ years, $43.1 \%$ were female, and $48.8 \%$ had $\geq 36$-month follow-up. The largest proportion of patients had health plans located in the Midwest (39.0\%), followed by $24.4 \%$ in the Northeast. Almost two-thirds (63.1\%) of the patients were enrolled in PPO health plans, as summarized in Table 1. The index event was ACS in $64.1 \%$ of patients who received high-intensity statin therapy in all four quarters following the index date. The most common baseline comorbidities of interest included pain (63.7\%), hypertension (47.0\%), dyslipidemia (35.3\%), and diabetes mellitus (16.4\%). At baseline, $\geq 1$ laboratory value was available for $20.8 \%(\mathrm{n}=26,653)$ of patients for LDL-C; $21.1 \%$ $(\mathrm{n}=26,964)$ for HDL-C; $21.2 \%(\mathrm{n}=27,196)$ for triglycerides; and $21.3 \%(n=27,292)$ for total cholesterol. Approximately one-quarter $(21.0 \%, \mathrm{n}=26,924)$ of patients $\mathrm{had} \geq 1$ non-HDL$\mathrm{C}$ value available. Among patients with baseline LDL-C values available, approximately $31.1 \%$ and $6.8 \%$ patients had LDL-C $<100 \mathrm{mg} / \mathrm{dL}$ and $<70 \mathrm{mg} / \mathrm{dL}$, respectively. For patients with available baseline HDL-C values, $65.5 \%$ had desirable HDL-C levels (defined as $>40 \mathrm{mg} / \mathrm{dL}$ for males and $>50 \mathrm{mg} / \mathrm{dL}$ for females). Antihypertensive medications (45.3\%) were the most commonly filled baseline medications, followed by antidiabetic medications $(9.8 \%)$ and prescription antiplatelet and anticoagulant medications (6.9\%).

\section{Use of LLMs at 12- and 36-month follow-up Index LLM}

Within 6 months after the index date, $61.4 \%$ had no fills for any LLM; $7.8 \%$ of the patients had initiated high-intensity statin monotherapy; $27.8 \%$ had initiated moderate-/lowintensity statin monotherapy; $1.6 \%$ had initiated non-statin monotherapy; and $1.4 \%$ had initiated combination therapy (data not shown in tables or figures).

Index LLM use by monotherapy initiators at 12- and 36-month follow-up

As summarized in Table 2, among all monotherapy initiators with 12-month follow-up ( $\mathrm{n}=47,587), 54.5 \%$ discontinued index LLM, 9.6\% switched their index LLM, 8.8\% had uptitration of index LLM, and $2.9 \%$ augmented index LLM within the 12-month follow-up. For monotherapy initiators with 36-month follow-up $(\mathrm{n}=21,198), 77.8 \%$ discontinued index LLM, 13.8\% switched their index LLM, 12.4\% had up-titration of index LLM, and $2.8 \%$ augmented index LLM over the 36-month follow-up period.

\section{LLM use among all patients at 12- and 36-month follow-up}

Overall, LLM utilization patterns among all patients showed that $41.4 \%$ received statins, $10.6 \%$ had high-intensity statins, $5.8 \%$ had been treated with $\geq 2$ types of statins, $4.9 \%$ had both statins and non-statin LLMs, and 56.9\% had no LLM within 12 months of follow-up. Among all patients, the mean (SD, median) number of LLM drug classes and LLM drug types filled within 12 months of follow-up was $0.5(0.6,0)$ and $0.5(0.7,0)$, respectively. Among patients with $\geq 36$ months of follow-up, $49.7 \%$ had statins, $13.0 \%$ had high-intensity statins, $12.8 \%$ had been treated with $\geq 2$ types of statins, $9.3 \%$ had both statins and non-statin LLMs, and $47.9 \%$ had no LLM during the 36-month follow-up period. Among patients with $\geq 36$ months of follow-up, the mean (SD, median) number of LLM drug classes and LLM drug types filled during the 36-month follow-up period was $0.6(0.7,1)$ and $0.8(0.9,1)$, respectively (data not shown in tables or figures). 
Table I Baseline demographic and clinical characteristics of ASCVD patients

\begin{tabular}{|c|c|c|c|c|c|c|c|c|c|c|}
\hline \multirow[t]{2}{*}{ Characteristics } & \multicolumn{2}{|c|}{ All patients } & \multicolumn{2}{|c|}{$\begin{array}{l}\text { Filled high-intensity } \\
\text { statins in all first } \\
\text { four quarters }\end{array}$} & \multicolumn{2}{|c|}{$\begin{array}{l}\text { With }>50 \% \text { LDL-C } \\
\text { reduction at } \\
\text { I 2-month } \\
\text { follow-up }\end{array}$} & \multicolumn{2}{|c|}{$\begin{array}{l}\text { With LDL-C } \\
<70 \text { mg/dL at } \\
\text { I 2-month } \\
\text { follow-up }\end{array}$} & \multicolumn{2}{|c|}{$\begin{array}{l}\text { With LDL-C } \\
<100 \mathrm{mg} / \mathrm{dL} \text { at } \\
\text { I2-month } \\
\text { follow-up }\end{array}$} \\
\hline & $\mathbf{n}$ & $\%$ & $\mathbf{n}$ & $\%$ & $\mathbf{n}$ & $\%$ & $\mathbf{n}$ & $\%$ & $\mathbf{n}$ & $\%$ \\
\hline Number of patients & 128,017 & 100 & 6,044 & 4.7 & 865 & $8.4^{*}$ & 3,556 & $19.9 *$ & 9,636 & $53.8 *$ \\
\hline Mean age (SD), median ${ }^{a}$ & $59(13)$ & 58 & $55(10)$ & 55 & $60(11)$ & 59 & $60(12)$ & 59 & $60(12)$ & 59 \\
\hline Female & 55,136 & 43.1 & 1,351 & 22.4 & 281 & 32.5 & 1,111 & 31.2 & 3,568 & 37.0 \\
\hline \multicolumn{11}{|l|}{ Geographic region } \\
\hline Northeast & 31,179 & 24.4 & 1,163 & 19.2 & 354 & 40.9 & $\mathrm{I}, 367$ & 38.4 & 3,978 & 41.3 \\
\hline Midwest & 49,979 & 39.0 & 2,503 & 41.4 & 189 & 21.9 & 865 & 24.3 & 2,215 & 23.0 \\
\hline South & 23,450 & 18.3 & $\mathrm{I}, 285$ & 21.3 & 199 & 23.0 & 734 & 20.6 & 1,967 & 20.4 \\
\hline West & 23,409 & 18.3 & 1,093 & 18.1 & 123 & 14.2 & 590 & 16.6 & $\mathrm{I}, 476$ & 15.3 \\
\hline \multicolumn{11}{|l|}{ Insurance plan type } \\
\hline $\mathrm{HMO}$ & 41,398 & 32.3 & I,585 & 26.2 & 433 & 50.1 & 1,690 & 47.5 & 4,786 & 49.7 \\
\hline PPO & 80,762 & 63.1 & 4,056 & 67.1 & 398 & 46.0 & 1,717 & 48.3 & 4,501 & 46.7 \\
\hline Others & 5,857 & 4.6 & 403 & 6.7 & 34 & 3.9 & 149 & 4.2 & 349 & 3.6 \\
\hline \multicolumn{11}{|l|}{ Type of ASCVD** } \\
\hline ACS & 26,887 & 21.0 & 3,873 & 64.1 & 298 & 34.5 & 1,233 & 34.7 & 2,564 & 26.6 \\
\hline $\mathrm{CHD}$ & 71,884 & 56.2 & 4,473 & 74.0 & 599 & 69.3 & 2,364 & 66.5 & 6,044 & 62.7 \\
\hline$A C D$ & 22,311 & 17.4 & 511 & 8.5 & 90 & 10.4 & 431 & 12.1 & 1,276 & 13.2 \\
\hline PAD & 23,457 & 18.3 & 123 & 2.0 & 93 & 10.8 & 439 & 12.4 & 1,552 & 16.1 \\
\hline $\mathrm{QCl}$, mean (SD), median ${ }^{\mathrm{a}}$ & $0.86(I .4 I)$ & 0.00 & $0.46(1.05)$ & 0.00 & $0.86(I .4 I)$ & 0.00 & $0.96(1.44)$ & 0.00 & $0.94(I .4 I)$ & 0.00 \\
\hline \multicolumn{11}{|l|}{$\begin{array}{l}\text { Selected comorbidities } \\
\text { of interest }\end{array}$} \\
\hline Anxiety & 9,619 & 7.5 & 320 & 5.3 & 44 & 5.1 & 180 & 5.1 & 549 & 5.7 \\
\hline Chronic kidney disease & 4,161 & 3.3 & 79 & 1.3 & 24 & 2.8 & 115 & 3.2 & 299 & 3.1 \\
\hline Depression & 7,599 & 5.9 & 232 & 3.8 & 44 & 5.1 & 156 & 4.4 & 423 & 4.4 \\
\hline Diabetes mellitus & 20,954 & 16.4 & 621 & 10.3 & 202 & 23.4 & 853 & 24.0 & 2,175 & 22.6 \\
\hline Dyslipidemia & 45,208 & 35.3 & $\mathrm{I}, 727$ & 28.6 & 488 & 56.4 & 1,440 & 40.5 & 4,038 & 41.9 \\
\hline Hypertension & 60,121 & 47.0 & 2,113 & 35.0 & 480 & 55.5 & 1,850 & 52.0 & 5,006 & 52.0 \\
\hline Obesity & 6,759 & 5.3 & 227 & 3.8 & 52 & 6.0 & 173 & 4.9 & 485 & 5.0 \\
\hline Pain & 81,501 & 63.7 & 3,068 & 50.8 & 575 & 66.5 & 2,182 & 61.4 & 6,037 & 62.7 \\
\hline \multicolumn{11}{|l|}{ Baseline lipid panel values ${ }^{\ddagger}, \S$} \\
\hline$\geq$ I LDL-C value available & 26,653 & 20.8 & 775 & 12.8 & 865 & 100.0 & 1,843 & 51.8 & 5,319 & 55.2 \\
\hline LDL-C $<100$ mg/dL & 8,279 & 31.1 & 137 & 17.7 & 89 & 10.3 & 977 & 53.0 & 2,518 & 47.3 \\
\hline LDL-C $<70 \mathrm{mg} / \mathrm{dL}$ & 1,803 & 6.8 & 35 & 4.5 & 5 & 0.6 & 418 & 22.7 & 637 & 12.0 \\
\hline$\geq \mathrm{I}$ HDL-C value available & 26,964 & 21.1 & 792 & 13.1 & 856 & 99.0 & 1,859 & 52.3 & 5,343 & 55.4 \\
\hline $\begin{array}{l}\mathrm{HDL}-\mathrm{C}>40 \mathrm{mg} / \mathrm{dL} \text { for } \\
\text { males, }>50 \mathrm{mg} / \mathrm{dL} \text { for } \\
\text { females }\end{array}$ & 17,655 & 65.5 & 437 & 55.2 & 539 & 63.0 & 1,106 & 59.5 & 3,380 & 63.3 \\
\hline $\begin{array}{l}\geq \text { I triglyceride value } \\
\text { available }\end{array}$ & 27,196 & 21.2 & 804 & 13.3 & 860 & 99.4 & 1,865 & 52.4 & 5,377 & 55.8 \\
\hline Triglycerides $<150 \mathrm{mg} / \mathrm{dL}$ & 17,757 & 65.3 & 459 & 57.1 & 500 & 58.1 & 1,158 & 62.1 & 3,480 & 64.7 \\
\hline $\begin{array}{l}\geq \mid \text { total cholesterol value } \\
\text { available }\end{array}$ & 27,292 & 21.3 & 808 & 13.4 & 860 & 99.4 & $\mathrm{I}, 870$ & 52.6 & 5,386 & 55.9 \\
\hline $\begin{array}{l}\text { Total cholesterol } \\
<200 \mathrm{mg} / \mathrm{dL}\end{array}$ & 14,703 & 53.9 & 307 & 38.0 & 244 & 28.4 & 1,359 & 72.7 & 3,640 & 67.6 \\
\hline $\begin{array}{l}\geq \mathrm{I} \text { non-HDL-C value } \\
\text { available }\end{array}$ & 26,924 & 21.0 & 792 & 13.1 & 854 & 98.7 & $\mathrm{I}, 857$ & 52.2 & 5,335 & 55.4 \\
\hline Non-HDL-C $<130 \mathrm{mg} / \mathrm{dL}$ & 9,780 & 36.3 & 153 & 19.3 & 108 & 12.6 & $\mathrm{I}, 00 \mathrm{I}$ & 53.9 & 2,701 & 50.6 \\
\hline \multicolumn{11}{|l|}{ Baseline medications } \\
\hline $\begin{array}{l}\text { Anti-claudication } \\
\text { medications }\end{array}$ & 445 & 0.4 & 9 & 0.2 & 4 & 0.5 & 13 & 0.4 & 31 & 0.3 \\
\hline Antidiabetic medications & $|2,56|$ & 9.8 & 472 & 7.8 & 140 & 16.2 & 571 & 16.1 & $\mathrm{I}, 400$ & 14.5 \\
\hline
\end{tabular}


Table I (Continued)

\begin{tabular}{|c|c|c|c|c|c|c|c|c|c|c|}
\hline \multirow[t]{2}{*}{ Characteristics } & \multicolumn{2}{|c|}{ All patients } & \multicolumn{2}{|c|}{$\begin{array}{l}\text { Filled high-intensity } \\
\text { statins in all first } \\
\text { four quarters }\end{array}$} & \multicolumn{2}{|c|}{$\begin{array}{l}\text { With }>50 \% \text { LDL-C } \\
\text { reduction at } \\
\text { I 2-month } \\
\text { follow-up }\end{array}$} & \multicolumn{2}{|c|}{$\begin{array}{l}\text { With LDL-C } \\
<70 \text { mg/dL at } \\
\text { I 2-month } \\
\text { follow-up }\end{array}$} & \multicolumn{2}{|c|}{$\begin{array}{l}\text { With LDL-C } \\
<100 \mathrm{mg} / \mathrm{dL} \text { at } \\
\text { I 2-month } \\
\text { follow-up }\end{array}$} \\
\hline & $\mathbf{n}$ & $\%$ & $\mathbf{n}$ & $\%$ & $\mathbf{n}$ & $\%$ & $\mathbf{n}$ & $\%$ & $\mathbf{n}$ & $\%$ \\
\hline $\begin{array}{l}\text { Antihypertensive } \\
\text { medications }\end{array}$ & 58,008 & 45.3 & 2,132 & 35.3 & 450 & 52.0 & 1,769 & 49.8 & 4,783 & 49.6 \\
\hline Digoxin & $2,2 \mid 4$ & $\mathrm{I} .7$ & 21 & 0.4 & 8 & 0.9 & 56 & 1.6 & 162 & 1.7 \\
\hline $\begin{array}{l}\text { Prescription antiplatelet } \\
\text { and anticoagulant } \\
\text { medications }\end{array}$ & 8,785 & 6.9 & 165 & 2.7 & 46 & 5.3 & 214 & 6.0 & 616 & 6.4 \\
\hline $\begin{array}{l}\text { Prescription omega } 3 \\
\text { fatty acids }\end{array}$ & 689 & 0.5 & 31 & 0.5 & 9 & 1.0 & 23 & 0.7 & 69 & 0.7 \\
\hline
\end{tabular}

Notes: ${ }^{\text {a }}$ ata presented as mean (SD), median.*The denominator for $8.4 \%$ was patients with valid LDL-C values at both baseline and I2-month follow-up ( $=10,297$ ); the denominator for $19.9 \%$ and $53.8 \%$ was patients with valid LDL-C values at I2-month follow-up $(n=17,915)$. **A patient could have multiple types of ASCVD on index date. ${ }^{*}$ In cases where there was more than one eligible baseline laboratory result for the same lipid measure, the one closest to index date was used. ${ }^{8}$ For each type of lipid panel value, the denominator for the percentage of patients with any given lipid level was the number of available patients with that lipid value.

Abbreviations: ACD, atherosclerotic cerebrovascular disease; ACS, acute coronary syndrome; ASCVD, atherosclerotic cardiovascular disease; CHD, coronary heart disease; HDL-C, high-density lipoprotein cholesterol; HMO, health maintenance organization; LDL-C, low-density lipoprotein cholesterol; PAD, peripheral artery disease; PPO, preferred provider organization; QCl, Quan-Charlson Comorbidity Index.

Table 2 Utilization patterns of index LLM among monotherapy initiators at 12- and 36-month follow-up

\begin{tabular}{|c|c|c|c|c|}
\hline \multirow[t]{2}{*}{ Utilization patterns } & \multicolumn{2}{|c|}{ I2-month follow-up } & \multicolumn{2}{|c|}{ 36-month follow-up } \\
\hline & $\mathbf{n}$ & $\%$ & $\mathbf{n}$ & $\%$ \\
\hline Number of monotherapy initiators & 47,587 & 100 & 21,198 & 100 \\
\hline \multicolumn{5}{|l|}{ Dose titration assessment } \\
\hline Up-titration of index LLM & 4,180 & 8.8 & 2,635 & 12.4 \\
\hline Down-titration of index LLM & 1,462 & 3.1 & 793 & 3.7 \\
\hline No dose change of index LLM & 41,945 & 88.1 & 17,770 & 83.8 \\
\hline \multicolumn{5}{|l|}{ Discontinuation/persistence } \\
\hline Discontinued index LLM & 25,938 & 54.5 & 16,488 & 77.8 \\
\hline Days from index fill date to first discontinuation date, mean (SD), median ${ }^{\mathrm{a}}$ & $116(91)$ & 90 & $270(274)$ & 155 \\
\hline Persistence of index LLM (days), mean (SD), median ${ }^{\mathrm{a}}$ & $219(133)$ & 242 & $449(4 \mid 2)$ & 275 \\
\hline \multicolumn{5}{|l|}{ Switch } \\
\hline Switched to non-index LLMs & 4,579 & 9.6 & 2,935 & 13.8 \\
\hline Days from index fill date to first switch date, mean (SD), median ${ }^{\mathrm{a}}$ & $129(88)$ & 101 & $293(278)$ & 173 \\
\hline \multicolumn{5}{|l|}{ Augmentation } \\
\hline Augmented index LLM & 1,403 & 2.9 & 586 & 2.8 \\
\hline Days from index fill date to first augmentation, mean (SD), median ${ }^{\mathrm{a}}$ & $157(92)$ & 157 & 310 (299) & 194 \\
\hline
\end{tabular}

Note: ${ }^{a}$ Data presented as mean (SD), median.

Abbreviation: LLM, lipid-lowering medication.

\section{All-cause and ASCVD-related HCRU and costs}

Baseline

Among all patients, $11.2 \%$ had baseline all-cause inpatient hospitalizations, $18.0 \%$ ER visits, $89.2 \%$ office visits, $84.8 \%$ other outpatient visits/services, and $82.6 \%$ pharmacy prescriptions. Baseline mean (SD, median) all-cause costs were $\$ 8,852$ (\$25,608, $\$ 3,379)$. Among patients with $\geq 36$ months of follow-up, $10.6 \%$ had baseline all-cause inpatient hospitalizations, $17.1 \%$ ER visits, $89.9 \%$ office visits, $85.9 \%$ other outpatient visits/services, and $84.2 \%$ pharmacy prescriptions.
Baseline mean (SD, median) all-cause costs were $\$ 8,375$ (\$24,962, \$3,490; data not shown in tables or figures).

\section{Follow-up}

During the 12-month follow-up period, $49.0 \%$ of all patients had all-cause inpatient hospitalizations while $42.0 \%$ had ASCVD-related inpatient hospitalizations. Patients on high-intensity statins in all four quarters had the highest proportion of all-cause (87.3\%) and ASCVD-related (86.5\%) inpatient hospitalizations (Figure 1). In the course of the 12-month follow-up period, mean (SD, median) all-cause 


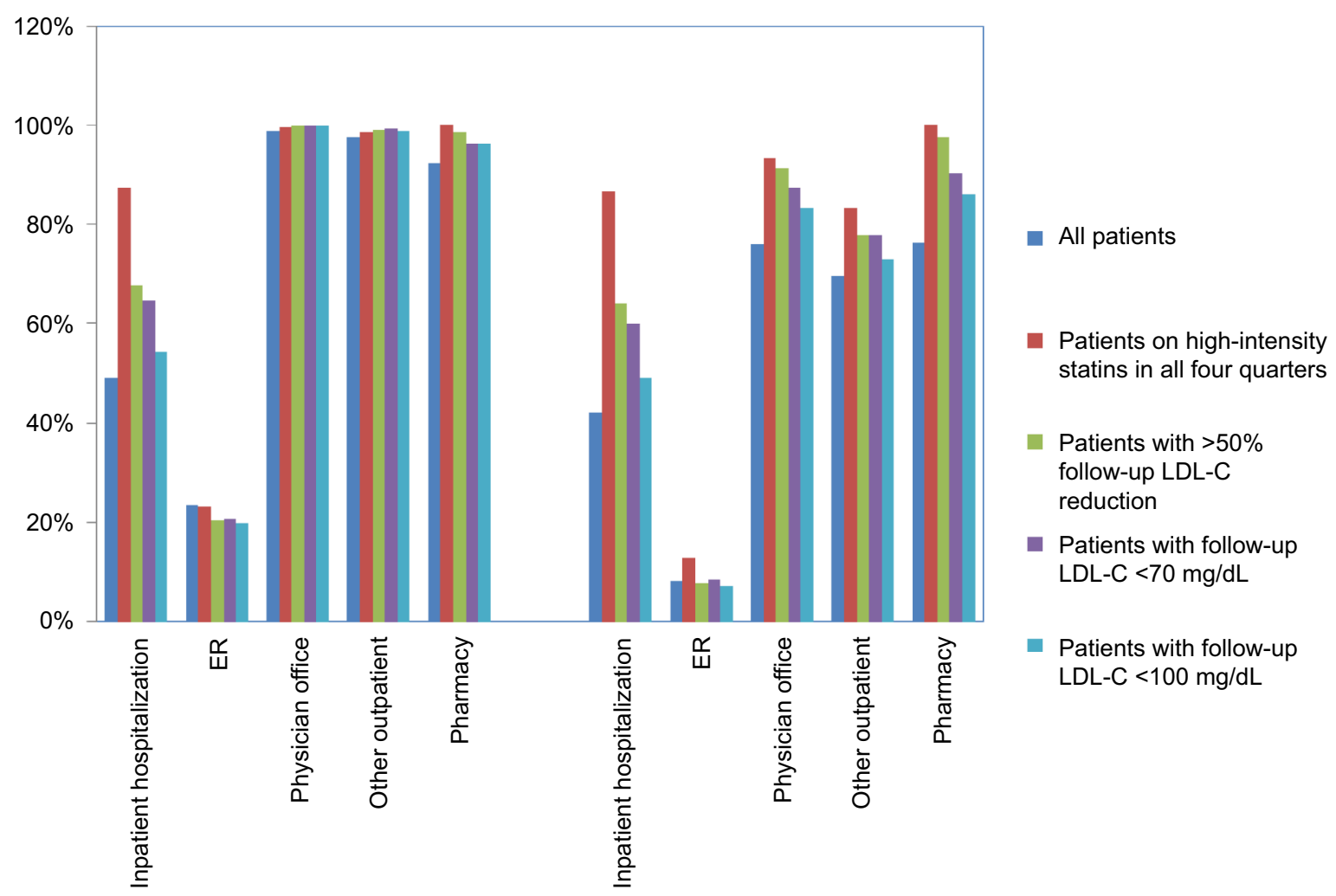

All-cause

ASCVD-related

Figure I All-cause and ASCVD-related HCRU over 12-month follow-up.

Note: The percentages in the figure show the percentage of patients with $\geq$ I specific visit or pharmacy fill.

Abbreviations: ASCVD, atherosclerotic cardiovascular disease; ER, emergency room; HCRU, health care resource utilization; LDL-C, low-density lipoprotein cholesterol.

costs for all patients were $\$ 31,443(\$ 54,040, \$ 15,389)$ while ASCVD-related costs were $\$ 20,289(\$ 45,159, \$ 4,510)$. Over the same duration, mean (SD, median) all-cause and ASCVD-related costs for patients on high-intensity statins in all four quarters were $\$ 56,324(\$ 52,954, \$ 43,714)$ and $\$ 50,015(\$ 49,969, \$ 38,202)$, respectively. During this period, patients with LDL-C reduction $>50 \%$ had mean (SD, median) all-cause costs of $\$ 42,988(\$ 53,980, \$ 31,164)$, followed by patients with LDL-C $<70 \mathrm{mg} / \mathrm{dL}(\$ 40,969$ $[\$ 53,143, \$ 28,118])$ and patients with LDL-C $<100 \mathrm{mg} /$ dL $(\$ 33,418$ [\$48,195, \$19,463]). Mean (SD, median) ASCVD-related costs over 12 months of follow-up among patients with LDL-C reduction $>50 \%$, LDL-C $<70 \mathrm{mg} / \mathrm{dL}$, and LDL-C $<100 \mathrm{mg} / \mathrm{dL}$ were $\$ 34,448(\$ 50,842, \$ 23,700)$, $\$ 31,771(\$ 48,609, \$ 20,146)$, and $\$ 24,577(\$ 43,824, \$ 8,632)$, respectively (Figure 2). The distributions of cumulative HCRU and costs over 36 months of follow-up among all patients and subgroups were similar to those over 12 months of follow-up (Figures S1 and S2).

\section{Multivariable analysis results}

\section{Baseline factors associated with all-cause and} ASCVD-related health care costs at 12-month follow-up

Regression models were used to evaluate patients' all-cause $(n=26,388)$ and ASCVD-related $(n=26,376)$ costs among subsamples of patients derived by excluding those with no baseline lipid values or with zero all-cause/ASCVD-related costs at follow-up. As shown in Figure 3, older age, health plan location including South and West (vs. Midwest), higher QCI, index ACS, index ACD, baseline depression, pain, obesity, and chronic kidney disease, baseline use of antihypertensive agents, antidiabetic medications, and digoxin, and higher baseline all-cause health care costs (in thousands) were positively associated with all-cause health care costs at 12 -month follow-up $(p<0.05)$. Factors negatively associated with all-cause health care costs at 12-month follow-up ( $p<$ 0.05 ) included female gender, Northeast plan (vs. Midwest), HMO (vs. PPO), Medicare Advantage Plans, index CHD, 


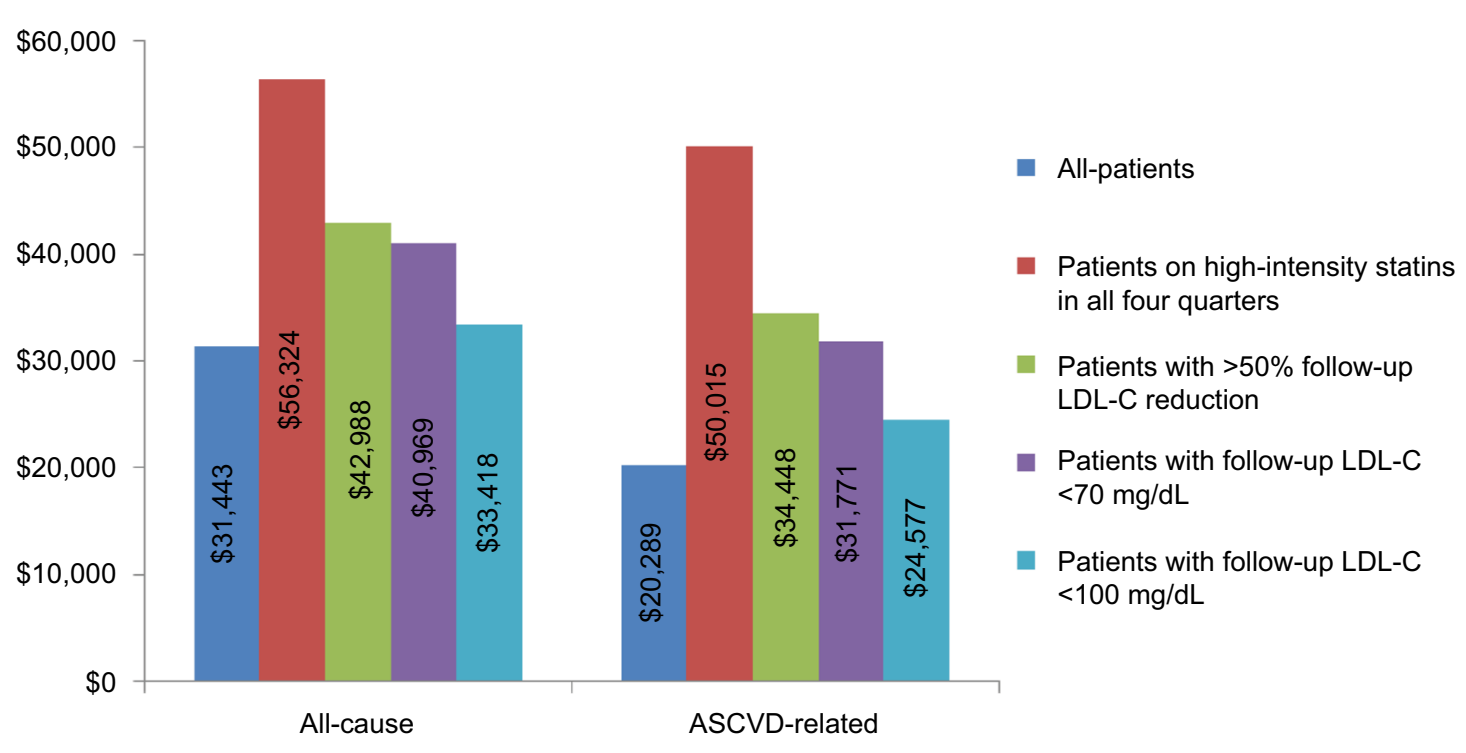

Figure 2 Mean all-cause and ASCVD-related costs over 12-month follow-up.

Note: Costs were adjusted to 2013 dollar values based on the consumer price index for medical care from the US Bureau of Labor Statistics. ${ }^{19}$

Abbreviations: ASCVD, atherosclerotic cardiovascular disease; LDL-C, low-density lipoprotein cholesterol.

index PAD, baseline dyslipidemia, baseline goal attainment of LDL-C ( $<100 \mathrm{mg} / \mathrm{dL})$, HDL-C ( $>40 / 50 \mathrm{mg} / \mathrm{dL}$ for males/ females, triglycerides $(<150 \mathrm{mg} / \mathrm{dL})$, and total cholesterol level $(<200 \mathrm{mg} / \mathrm{dL})$. Similar findings were reported for ASCVD-related health care costs at 12-month follow-up (Figure S3).

\section{Discussion and conclusion}

The study provided insights into demographics and clinical characteristics, short-term and long-term LLM utilization patterns, and HCRU and costs of newly diagnosed ASCVD patients in a real-world environment. It incorporated features from the older and current guidelines to expand the scope and volume of information on disease burden and gaps in care among ASCVD patients as defined by the 2013 ACC/ AHA guidelines. ${ }^{5}$

In this study population, only a small proportion of patients initiated high-intensity statins within 6 months of an ASCVD diagnosis, a trend that persisted through the 12- and 36-month follow-up assessments. Low rates of highintensity statin fills have been reported in several studies, for example, Virani et a ${ }^{21}$ (36.5\% among cardiovascular disease patients who received statins within a 1-year observational period) and Rosenson et $\mathrm{al}^{22}$ (35.0\% within 365 days of discharge among patients with hospitalizations for a CHD event). Particularly concerning is the finding that at both 12- and 36-month follow-up, approximately half of the patients with ASCVD were receiving no LLM. These results showed that the treatment received by ASCVD patients prior to implementation of the 2013 ACC/AHA guidelines was very different from what the 2013 ACC/AHA guidelines recommend. Pencina et a ${ }^{14}$ estimated that the 2013 ACC/ AHA guidelines would increase statin eligibility by $11 \%$ in the USA, or by 12.8 million patients when compared with the ATP-III guidelines. However, the current study results (large proportion of patients not on high-intensity statins or not on any LLM, and large proportion of patients with index LLM discontinuation) indicate that there may be a need for considerable modifications in prescribing patterns designed to help patients access the potential benefits of high-intensity statins, ${ }^{5,23-25}$ and improving treatment outcomes as indicated in the 2013 ACC/AHA guidelines. ${ }^{5}$

Our findings indicated that ASCVD patients, who were on intensive statin therapy according to the 2013 ACC/AHA guideline recommendations ${ }^{5}$ or met the NCEP ATP III guidelines ${ }^{13}$ on LDL-C goal attainment, had significant HCRU and costs associated with residual risk. These findings most likely reflect more aggressive statin use by patients considered to be at highest risk (with risk, rather than statin use as the driver of HCRU). As the 2013 ACC/AHA guidelines become better entrenched and the recommendations for high-intensity statin therapy proliferate across a broader spectrum of ASCVD patients with varying severity and risk profiles, it seems plausible for the economic burden associated with high-intensity statin therapy to decrease, perhaps eventually leading to overall health care savings. As new technologies emerge with the ability to further optimize the lipid profile beyond what high-intensity statin therapies can achieve alone, there may 


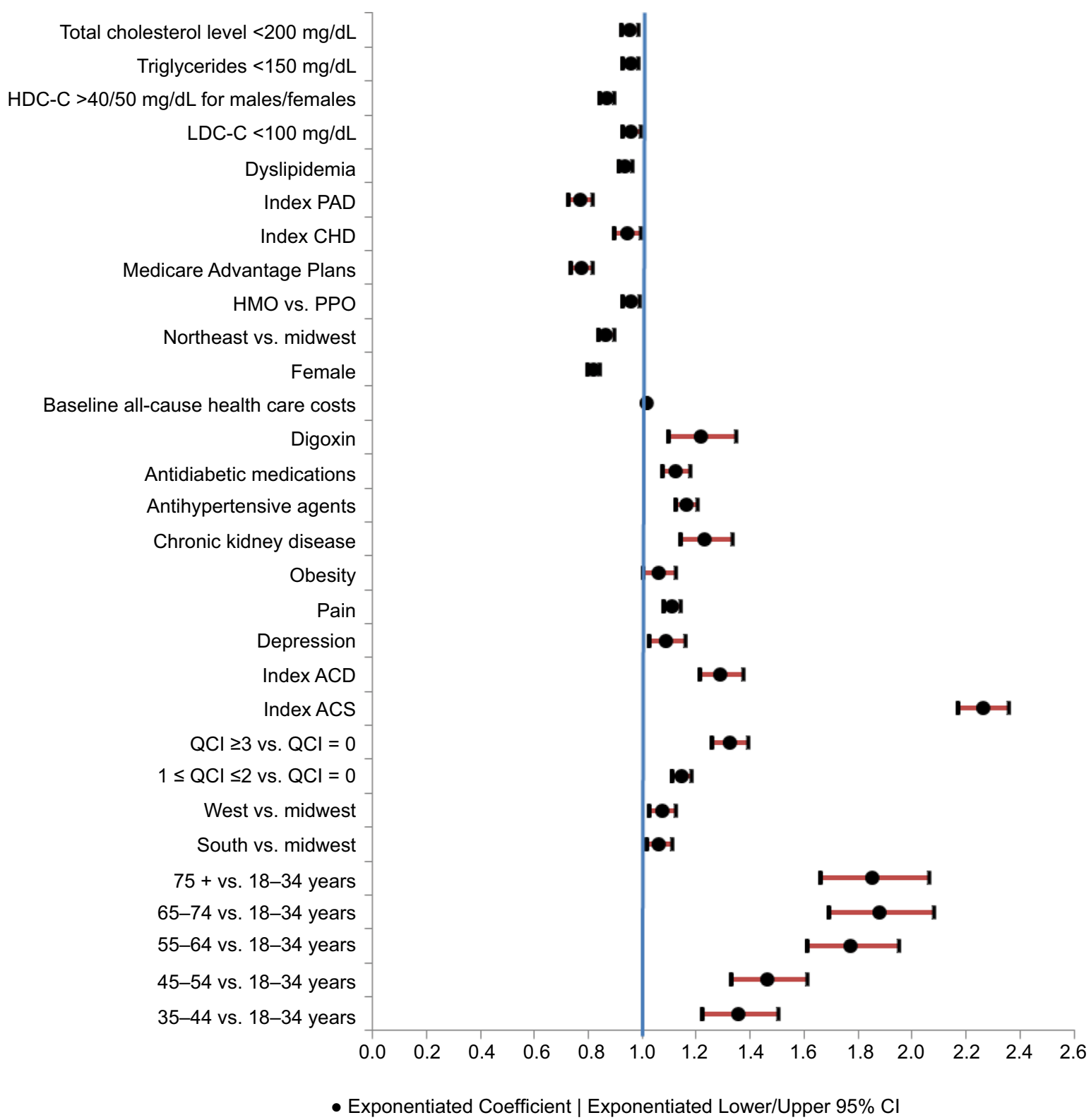

Figure 3 GLM results: baseline factors associated with all-cause health care costs over 12-month follow-up.

Notes: Dependent variable: all-cause health care costs at I2-month follow-up. Costs were adjusted to 2013 dollar values based on the consumer price index for medical care from the US Bureau of Labor Statistics. ${ }^{19}$

Abbreviations: ACD, atherosclerotic cerebrovascular disease; ACS, acute coronary syndrome; CHD, coronary heart disease; GLM, generalized linear model; HDL-C, highdensity lipoprotein cholesterol; HMO, health maintenance organization; LDL-C, low-density lipoprotein cholesterol; PAD, peripheral artery disease; PPO, preferred provider organization; QCl, Quan-Charlson Comorbidity Index.

be similar opportunities to optimize residual risk and impact HCRU and costs among patients with clinical ASCVD.

The study also indicated that age, gender, baseline comorbid conditions, baseline use of specific medications, baseline lipid profiles, and the type of index ASCVD were significantly associated with all-cause and ASCVD-related health care costs. Female gender may be negatively associated with all-cause and ASCVD-related health care costs because there may be a tendency for women to be undertreated, ${ }^{26}$ although relevant questions such as gender-based help-seeking decisions in cardiology are quite complex and not well understood. ${ }^{26}$ Further study is needed to test whether this is changing in the absence of specific gender differences for treating ASCVD based on the more recent ACC/AHA guidelines. ${ }^{5,27}$ Geographic location and health insurance type are also significantly associated with health care costs among ASCVD patients in this study. Compared to patients with health plans located in the Midwest, those enrolled in Northeast health plans were significantly associated with lower all-cause health care costs, while those with health plans located in the South or West regions were significantly associated with higher all-cause health care costs. 
Furthermore, patients enrolled in PPOs were significantly associated with higher all-cause health care costs when compared to patients enrolled in other types of health plans (HMOs or other). These multivariable results suggested that HCRU and costs of ASCVD patients were impacted by multiple patient demographic and clinical characteristics. Clinicians may want to take these factors into consideration to achieve optimal management of ASCVD patients according to the 2013 ACC/AHA guideline recommendations.

\section{Limitations}

The study results must be approached with caution because of limitations associated with transactional claims data repurposed for research. First, in addition to the potential for miscoding, incompleteness and other errors, a claim for a filled prescription does not necessarily mean that the medication was consumed or taken as prescribed. On the other hand, the absence of a prescription claim does not necessarily mean that a medication was not taken; for example, patients may purchase medications directly or acquire them from pharmacies that do not submit claims or obtain professional samples from physicians. Thus, LLM utilization in this study could have been underestimated or overestimated. Furthermore, patients with ASCVD have a class 1 (level of evidence $-\mathrm{A}$ ) recommendation for statin therapy "and" aspirin (except where contraindicated). ${ }^{28}$ However, in claims-based studies, nonprescription antiplatelet therapy (such as aspirin) use cannot be evaluated, underscoring the challenges of obtaining a full utilization picture. Therefore, the numbers listed in Table $1(n=8,785$ [6.9\%]) refer only to prescription antiplatelet therapy. In addition, as only some subgroups of patients with ASCVD carry a recommendation for prescription antiplatelet therapy (either because of intolerance to aspirin or the need for dual therapy), it is expected that usage of prescription antiplatelet therapy would be lower than that of LLMs. Second, a diagnosis code on a medical claim does not necessarily indicate the presence of a disease, as a diagnosis code may be incorrectly coded or included as a ruled-out diagnosis. To address this issue, we required $\geq 1$ inpatient or ER visit with any ASCVD ICD-9-CM diagnosis codes in the primary diagnosis position or $\geq 2$ physician office or other outpatient visits that were $\geq 30$ days apart with the same group of ASCVD ICD-9-CM diagnosis codes for identification of the ASCVD patients. Third, it is generally acknowledged that some patient characteristics that may be expected to affect risk and costs are not available in claims data (family history, smoking status, diet, exercise, severity of ASCVD, etc). Finally, our multivariable analyses were restricted to patients with available laboratory data. These results may not be generalizable to all patients in the HIRD, or to patients in noncommercial health plans or without any health insurance, or to patients who had any LLM use prior to their ASCVD diagnoses.

\section{Conclusion}

The findings suggest that treatment for ASCVD patients was not optimal and significant modifications in prescribing patterns should be made toward the use of high-intensity statins to improve treatment outcomes in accordance with the 2013 ACC/AHA guidelines. ${ }^{5}$ The findings indicated that ASCVD patients had significant residual HCRU and costs. Furthermore, age, gender, geographic location, health insurance type, baseline comorbid conditions, baseline use of specific medications, baseline lipid profiles, and type of index ASCVD were significantly associated with all-cause and ASCVD-related health care costs. Unmet needs, including association of suboptimal treatment with future cardiovascular events, and cost burdens of ASCVD patients merit additional investigation.

\section{Acknowledgments}

Bernard B Tulsi, MSc, provided writing and other editorial support for this manuscript. We wish to recognize Debra Wertz, PharmD, Senior Director at HealthCore, Inc., for her critical review and guidance throughout the study, and in the preparation of this manuscript. This study was supported by Eli Lilly and Company.

\section{Disclosure}

Thomas P Power is an employee of AIM Specialty Health, a wholly owned subsidiary of Anthem, Inc. Xuehua Ke, Mark J Cziraky, Michael Grabner, John J Barron, and Ralph Quimbo are employees of HealthCore, Inc., a wholly owned subsidiary of Anthem, Inc., under contract with Eli Lilly and Company for the conduct of this study. Nicole Gidaya Bonine was an employee of HealthCore, Inc., under contract with Eli Lilly and Company for the conduct of this study at the time of the study. Zhenxiang Zhao and Burkhard Vangerow are employees and stock/shareholders of Eli Lilly and Company. Peter P Toth is an employee of CGH Medical Center and an adjunct associate professor at Johns Hopkins University School of Medicine, under contract with HealthCore, Inc.; has relationships for the following: speakers bureau-Amarin Corporation, AstraZeneca Plc, Genzyme Corporation, GlaxoSmithKline Plc, Kowa Pharmaceuticals America, Inc., and Merck \& Co., Inc.; consultant - Amgen, AstraZeneca Plc, Atherotech Diagnostics 
Lab, Kowa Pharmaceuticals America, Inc., Liposcience, Inc., Merck \& Co., Inc., and Novartis Pharmaceuticals Corporation. The authors report no other conflicts of interest in this work.

\section{References}

1. Centers for Disease Control and Prevention, National Center for Health Statistics [webpage on the Internet]. Underlying Cause of Death 19992013 on CDC WONDER Online Database, Released 2015. Data Are from the Multiple Cause of Death Files, 1999-2013, as Compiled from Data Provided by the 57 Vital Statistics Jurisdictions through the Vital Statistics Cooperative Program. 2015. Available from: http://wonder. cdc.gov/ucd-icd10.html. Accessed February 3, 2015.

2. U.S. Census Bureau. The next four decades. The older population in the United States: 2010 to 2050. Washington, DC: U.S. Department of Commerce; 2010. Available from: https://www.census.gov/prod/2010pubs/ p25-1138.pdf. Accessed June 14, 2015.

3. Heidenreich PA, Trogdon JG, Khavjou OA, et al; American Heart Association Advocacy Coordinating Committee; Stroke Council; Council on Cardiovascular Radiology and Intervention; Council on Clinical Cardiology; Council on Epidemiology and Prevention; Council on Arteriosclerosis; Thrombosis and Vascular Biology; Council on Cardiopulmonary; Critical Care; Perioperative and Resuscitation; Council on Cardiovascular Nursing; Council on the Kidney in Cardiovascular Disease; Council on Cardiovascular Surgery and Anesthesia, and Interdisciplinary Council on Quality of Care and Outcomes Research. Forecasting the future of cardiovascular disease in the United States: a policy statement from the American Heart Association. Circulation. 2011;123(8):933-944.

4. Grundy SM, Cleeman JI, Merz CN, et al; American College of Cardiology F and American Heart A. Implications of recent clinical trials for the National Cholesterol Education Program Adult Treatment Panel III guidelines. Circulation. 2004;110:227-239.

5. Stone NJ, Robinson JG, Lichtenstein AH, et al; American College of Cardiology/American Heart Association Task Force on Practice G. 2013 ACC/AHA guideline on the treatment of blood cholesterol to reduce atherosclerotic cardiovascular risk in adults: a report of the American College of Cardiology/American Heart Association Task Force on Practice Guidelines. Circulation. 2014;129(25 suppl 2):S1-S45.

6. Baigent C, Keech A, Kearney PM, et al; Cholesterol Treatment Trialists C. Efficacy and safety of cholesterol-lowering treatment: prospective meta-analysis of data from 90,056 participants in 14 randomised trials of statins. Lancet. 2005;366(9493):1267-1278.

7. Cholesterol Treatment Trialists' (CTT) Collaboration, Baigent C, Blackwell L, et al. Efficacy and safety of more intensive lowering of LDL cholesterol: a meta-analysis of data from 170,000 participants in 26 randomised trials. Lancet. 2010;376(9753):1670-1681.

8. Cholesterol Treatment Trialists C, Mihaylova B, Emberson J, et al. The effects of lowering LDL cholesterol with statin therapy in people at low risk of vascular disease: meta-analysis of individual data from 27 randomised trials. Lancet. 2012;380(9841):581-590.

9. Ling G. Antiplatelet therapy for secondary prevention in stroke making the right choice. Curr Vasc Pharmacol. 2012;10(2):225-237.

10. Thavendiranathan P, Bagai A, Brookhart MA, Choudhry NK. Primary prevention of cardiovascular diseases with statin therapy: a meta-analysis of randomized controlled trials. Arch Intern Med. 2006;166(21):2307-2313.

11. Cannon CP. The next step in cardiovascular protection. Atheroscler Suppl. 2003;4(5):3-9.
12. LaRosa JC. At the heart of the statin benefit. J Am Coll Cardiol. 2005;46(10): 1863 .

13. National Cholesterol Education Program Expert Panel on Detection E and Treatment of High Blood Cholesterol in A. Third Report of the National Cholesterol Education Program (NCEP) expert panel on detection, evaluation, and treatment of high blood cholesterol in adults (Adult Treatment Panel III) final report. Circulation. 2002;106(25):3143-3421.

14. Pencina MJ, Navar-Boggan AM, D'Agostino RB Sr, et al. Application of new cholesterol guidelines to a population-based sample. $N$ Engl $J$ Med. 2014;370(15):1422-1431.

15. Koenigsfeld C, Sayler M, Smith HL, et al. Retrospective evaluation of ASCVD risk and statin therapy need in nondiabetic patients based on the 2013 ACC/AHA cholesterol guidelines. J Pharm Pract. 2017;30(3):300-305.

16. Tran JN, Caglar T, Stockl KM, Lew HC, Solow BK, Chan PS. Impact of the new ACC/AHA guidelines on the treatment of high blood cholesterol in a managed care setting. Am Health Drug Benefits. 2014;7(8):430-443.

17. Wasser T, We B, Ycas J, Tunceli O. Applying weighting methodologies to a commercial database to project US Census Demographic Data. Am J Acc Care. 2015;9.15:33-38.

18. Quan $\mathrm{H}$, Sundararajan V, Halfon $\mathrm{P}$, et al. Coding algorithms for defining comorbidities in ICD-9-CM and ICD-10 administrative data. Med Care. 2005;43:1130-1139.

19. U.S. Bureau of Labor Statistics [database on the Internet]. Consumer Price Index (CPI) for Medical Care. 2014. Available from: http://data. bls.gov. Accessed March 6, 2014.

20. Moran JL, Solomon PJ, Peisach AR, Martin J. New models for old questions: generalized linear models for cost prediction. $J$ Eval Clin Pract. 2007;13(3):381-389.

21. Virani SS, Woodard LD, Akeroyd JM, Ramsey DJ, Ballantyne CM, Petersen LA. Is high-intensity statin therapy associated with lower statin adherence compared with low- to moderate-intensity statin therapy? Implications of the 2013 American College of Cardiology/American Heart Association Cholesterol Management Guidelines. Clin Cardiol. 2014;37(11):653-659.

22. Rosenson RS, Kent ST, Brown TM, et al. Underutilization of highintensity statin therapy after hospitalization for coronary heart disease. J Am Coll Cardiol. 2015;65(3):270-277.

23. Jacobson TA, Ito MK, Maki KC, et al. National Lipid Association recommendations for patient-centered management of dyslipidemia: part 1 - executive summary. J Clin Lipidol. 2014;8(5):473-488.

24. Raymond C, Cho L, Rocco M, Hazen SL. New cholesterol guidelines: worth the wait? Cleve Clin J Med. 2014;81(1):11-19.

25. Colantonio LD, Huang L, Monda KL, et al. Adherence to high-intensity statins following a myocardial infarction hospitalization among Medicare beneficiaries. JAMA Cardiol. 2017;2(8):890-895.

26. Stain N, Ridge D, Cheshire A. Gender comparisons in non-acute cardiac symptom recognition and subsequent help-seeking decisions: a mixed methods study protocol. BMJ Open. 2014;4(10):e005742.

27. Gulati M, Merz CN. New cholesterol guidelines and primary prevention in women. Trends Cardiovasc Med. 2015;25(2):84-94.

28. Fihn SD, Gardin JM, Abrams J, et al 2012 ACCF/AHA/ACP/AATS/ PCNA/SCAI/STS Guideline for the diagnosis and management of patients with stable ischemic heart disease: a report of the American College of Cardiology Foundation/American Heart Association Task Force on Practice Guidelines, and the American College of Physicians, American Association for Thoracic Surgery, Preventive Cardiovascular Nurses Association, Society for Cardiovascular Angiography and Interventions, and Society of Thoracic Surgeons. J Am Coll Cardiol. 2012;60(24):e44-e164. 


\section{Supplementary materials}

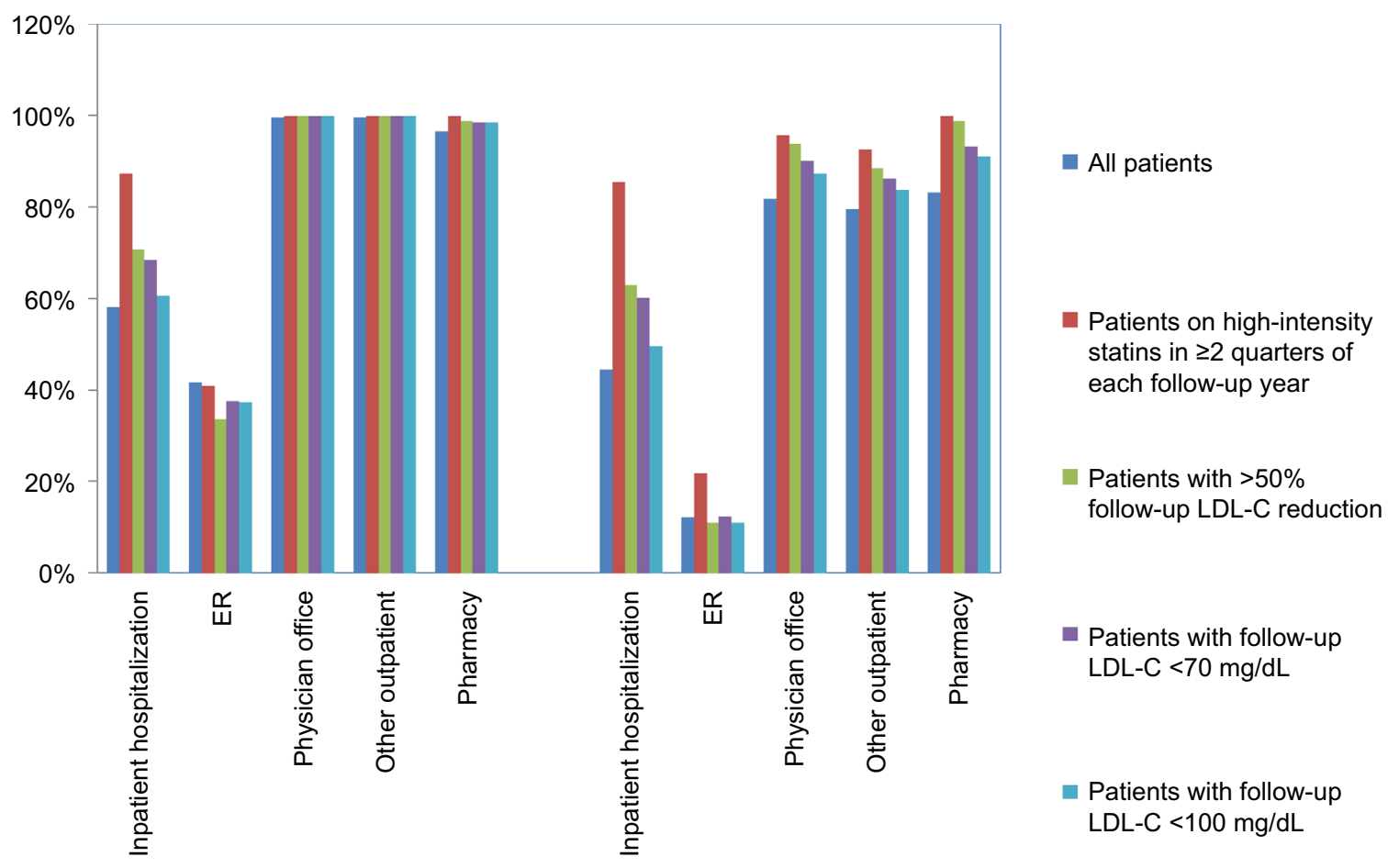

All-cause

ASCVD-related

Figure SI Cumulative all-cause and ASCVD-related HCRU over 36-month follow-up.

Note: The percentages in the figure show the percentage of patients with $\geq 1$ specific visit or pharmacy fill.

Abbreviations: ASCVD, atherosclerotic cardiovascular disease; ER, emergency room; HCRU, health care resource utilization; LDL-C, low-density lipoprotein cholesterol.

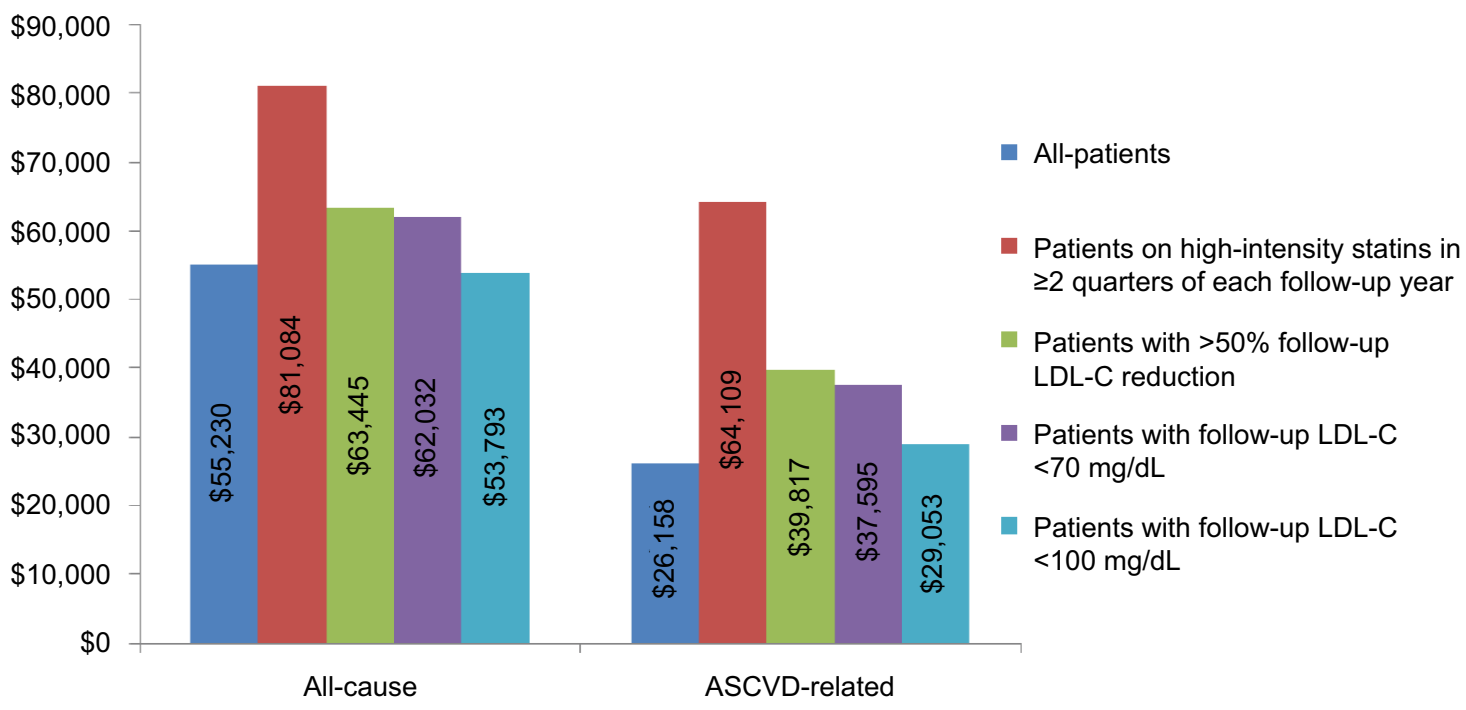

Figure S2 Mean cumulative all-cause and ASCVD-related costs over 36-month follow-up.

Note: Costs were adjusted to 2013 dollar values based on the consumer price index for medical care from the US Bureau of Labor Statistics. ${ }^{19}$

Abbreviations: ASCVD, atherosclerotic cardiovascular disease; LDL-C, low-density lipoprotein cholesterol. 
Table SI ASCVD groups

\begin{tabular}{llll}
\hline Group & Type & Diseases/events & ICD-9-CM diagnosis code \\
\hline I & ACS & MI & $4 I 0 . x x$ \\
& & Unstable angina & $4 I I .1 x, 4 I I .8 I, 4 I I .89$ \\
& CHD & Old MI & $4 I 2 . x x$ \\
& & Stable angina & $4 I 3 . x x$ \\
2 & Coronary atherosclerosis & $4 I 4.0 x, 4 I 4.2 x, 4 I 4.3 x, 4 I 4.4 x, 4 I 4.8 x$ \\
3 & ACD & Ischemic stroke & $433 . x I, 434 . x I$ \\
& PAD & PIA & $435 . x x$ \\
\end{tabular}

Abbreviations: ACD, atherosclerotic cerebrovascular disease; ACS, acute coronary syndrome; ASCVD, atherosclerotic cardiovascular disease; CHD, coronary heart disease; MI, myocardial infarction; PAD, peripheral artery disease; TIA, transient ischemic attack.

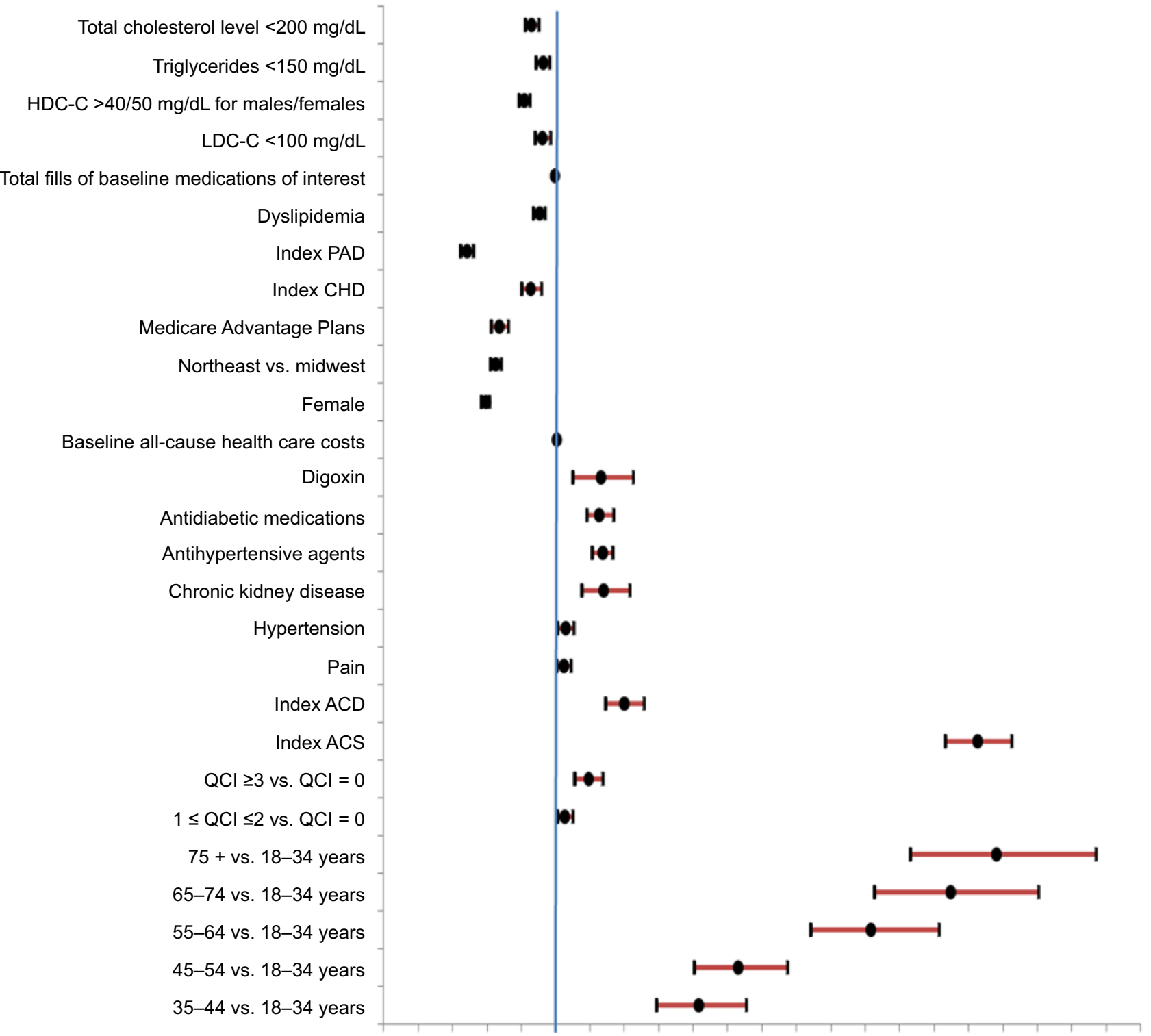

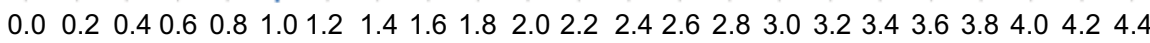

- Exponentiated Coefficient | Exponentiated Lower/Upper 95\% Cl

Figure S3 GLM results: baseline factors associated with ASCVD-related health care costs over 12-month follow-up.

Notes: Dependent variable: ASCVD-related health care costs at 12-month follow-up. Baseline medications of interest: anti-claudication medications, antidiabetic medications, antihypertensive medications, digoxin, prescription antiplatelet and anticoagulant medications, and prescription omega 3 fatty acids. Costs were adjusted to 2013 dollar values based on the consumer price index for medical care from the US Bureau of Labor Statistics. ${ }^{19}$

Abbreviations: ACD, atherosclerotic cerebrovascular disease; ACS, acute coronary syndrome; ASCVD, atherosclerotic cardiovascular disease; CHD, coronary heart disease; GLM, generalized linear model; HDL-C, high-density lipoprotein cholesterol; LDL-C, low-density lipoprotein cholesterol; PAD, peripheral artery disease; QCI, Quan-Charlson Comorbidity Index. 


\section{Publish your work in this journal}

Vascular Health and Risk Management is an international, peerreviewed journal of therapeutics and risk management, focusing on concise rapid reporting of clinical studies on the processes involved in the maintenance of vascular health; the monitoring, prevention and treatment of vascular disease and its sequelae; and the involvement of metabolic disorders, particularly diabetes. This journal is indexed on PubMed Central and MedLine. The manuscript management system is completely online and includes a very quick and fair peer-review system, which is all easy to use. Visit http://www.dovepress.com/ testimonials.php to read real quotes from published authors. 